\title{
ANSYS-Based Structural Analysis Study of Elevated Spherical Tank Exposed to Earthquake
}

\author{
Mahmoud S. Al-Khafaji ${ }^{a^{*}}$, Ahlam S. Mohammed (D) b, Muna A.Salman ${ }^{c}$ \\ a'University of Technology, Baghdad, Iraq, 41100@uotechnology.edu.iq

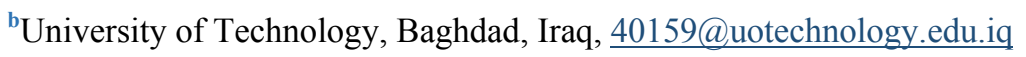 \\ 'University of Technology, Baghdad, Iraq, mengme58@Gmail.com \\ *Corresponding author.
}

Submitted: 15/07/2019

Accepted: 21/10/2019

Published: 25/06/2021

\section{K E Y W O R D S}

ANSYS, earthquake, elevated tank, Finite Element, natural frequencies.

\begin{abstract}
A B S T R A C T
Damage of elevated tanks during earthquakes can jeopardize the supply of drinking water and causes significant economic losses. Therefore, seismic analysis of tanks containing liquids requires special consideration. Knowledge of liquid hydrodynamic pressures developed during an earthquake is important for tank design. This paper aims to verify the dynamic reaction of structural systems of spherical elevated steel tanks containing water, and determine the natural frequencies that contribute to the physical response, as well as seismic analysis of the tank. A three dimensional Finite Element Model was developed to identify the main parameters involved in this response for three different fullness ratio $(0.00 \%, 53.30 \%$ and $71.11 \%)$ using the ANSYS software. The model was implemented and validated based on the results of a previously conducted experimental study. Moreover, it was analyzed under the impact of the most severe earthquake that Iraq was exposed to in 2017 with a magnitude of 7.2 on the Richter scale. The results showed a very good agreement in natural frequency with a discrepancy (root mean square error) of $2 \%$ $(0.05 \mathrm{~Hz}), 6.9 \%(0.15 \mathrm{~Hz})$ and $9.5 \%(0.2 \mathrm{~Hz})$ for the fullness ratio $0 \%$, $53.3 \%$ and $71.11 \%$, respectively In addition, the selected element type and the method of analysis are applicable. Moreover, results of displacement and stresses from earthquake analysis indicated that the spherical tank could lose stability in time 1.4 seconds of the proposed time for the worst part of the earthquake, when displacement records highest values in the direction of earthquake for the tank body at chosen points in the top, middle, and bottom of the tank body which were almost equally at all cases proposed in this study.
\end{abstract}

How to cite this article: M.S. Al-Khafaji, A. S. Mohammed, and M. A. Salman, "ANSYS-Based Structural Analysis Study of Elevated Spherical Tank Exposed to Earthquake" Engineering and Technology Journal, Vol. 39, No.6, pp.870-883, 2021.

DOI: https://doi.org/10.30684/etj.v39i6.460

This is an open access article under the CC BY 4.0 license http://creativecommons.org/licenses/by/4.0 


\section{INTRODUCTION}

Water tanks are of great interest to the designer, construction and water resources engineers for their necessity and their need to preserve human life in urban areas. They represent a main part of the water treatment and transport system, which is one of the most important parts of the service systems in urban areas. Recently, urbanization and increase in residential and economic projects increase the domestic water demand with highly fluctuated rate. This makes using the water tanks, essential for sustaining life. Because the elevated tanks are frequently used in seismic active regions, seismic behavior must be studied in detail. The dynamic behavior of liquid storage tanks has an increasing importance during the last few decades. Furthermore, a special attention is given to the response of these structures to vibration transmitted through the ground by earthquakes, traffic, pile driving hammers, explosions, etc. In the design of the tank, the hydrodynamic pressure of tanks under earthquake forces plays an important role. Earthquake in elevated water tanks can induce large horizontal and overturning forces [1].

Iraq nowadays is subject to seismic activity by virtue of its location. Recently, the risk of earthquakes has been increased significantly, according to relevant sources of seismic monitoring [2, $-4]$.

The earlier works on elevated tanks were presented by George W. Housner (1963)[5]. In this work, the relationship between the water movement with respect to the tank and the motion of the whole structure with respect to the ground was discussed. Three basic conditions were considered for analysis, i.e. empty tank, partially filled tank and fully filled tank. This study concluded that the maximum force subjected to the partially filling tank is less than half the force subjected to the full tank. The actual forces on the basis of a complete tank can be as small as $1 / 3$ of the anticipated forces.

Haroun and Temraz (1992)[6] analyzed two-dimensional x-braced elevated tanks supported on isolated footings to investigate the impact of the dynamic interaction between the tower and the supporting soil foundation system, the effect of sloshing was neglected in their work.

The dynamic analysis of cylindrical liquid storage tanks supported by the ground was investigated by Seyoum (2005)[7], an assumption of elastic materials and adoption of linear theory was dependent, the liquid sloshing effects was included. Finite element method has been used and the results have been compared with the results of the approximate method of Housner (1963). ANSYS finite element software was used to model this system with the adoption of spectrum response technique. Coupled frequencies were found to be higher than sloshing frequencies. Housner's method has also been found to underestimate the shear stress in most cases. Dutta et al. (2004) [8] presented a comprehensive study on the dynamic characteristics of reinforced concrete (RC) elevated tanks with cylindrical shaft staging support. The results were analytically validated using analysis of finite element and experimentation on a small scale. Amani et al. (2010) [9] evaluated the resonant frequencies in the RC spherical container partially filled with water using the finite element method and experimentally verified the results. The main finding was that for the spherical tank, essentially three independent mass-motions are necessary; translation (structural),"sloshing (convective) and pendulum motions. Therefore, three degrees of freedom are required for the analysis [10]. Suchita. and Manoj (2011) [11] evaluated the seismic performance of high water tanks for different Indian zones, for different heights and tank capacity for different soil conditions. The main conclusion was that seismic forces increase with zones and decrease with, supporting "system height, seismic forces are higher in soft soil than medium soil, higher in medium soil than hard soil. Soft soil earthquake forces are about $40-41 \%$ higher than hard soil forces in all earthquake zones.

In this study, a plastic spherical tank was analyzed numerically under the impact of an earthquake that Iraq was previously exposed in 2017 with a magnitude of 7.2 on the Richter scale, which was considered as the most dangerous case according to the reports and the competent authorities of seismic monitoring. To verify the FEM, the computed natural frequencies, were compared with that of experimental analysis of O.Curadelli et.al (2008)[12]. This experimental analysis was chosen to be a comparison reference because it contains experimental work of a plastic spherical tank, which is the commonly used tank shape. O.Curadelli (2008) considered three different fullness ratios $(0.00 \%$, $53.30 \%$ and $71.11 \%$ ). In this study, the same fullness ratios were considered to perform the calibration and verification process. 


\section{Materials AND MethodS}

\section{Description of Structure}

As mentioned previously, all the dimensions and material properties of the present work was taken from O. Curadelli et.al (2008) [12]. Figure 1 shows the considered elevated plastic spherical tank, the contained liquid is water, following are the properties of the tank:

- Volume of tank $(\mathrm{V})=0.00225 \mathrm{~m}^{3}$.

- Density of water $\left(\rho_{\mathrm{w}}\right)=1000 \mathrm{~kg} / \mathrm{m}^{3}$.

- The radius of the tank $(\mathrm{R})=0.0813 \mathrm{~m}$.

- Shell thickness $(\mathrm{t})=0.003 \mathrm{~m}$.

- The density of the tank plastic material $\left(\rho_{\mathrm{s}}\right)=980 \mathrm{~kg} / \mathrm{m}^{3}$.

The support consists of two clamped legs at the base with the following details:

- $\quad$ Length $(\mathrm{L})=0.26 \mathrm{~m}$.

- Cross section area $(\mathrm{A})=0.003 \times 0.0035 \mathrm{~m}^{2}$.

- Young modulus of elasticity $(\mathrm{E})=2.35 \times 10^{9} \mathrm{~Pa}$.

- Poisson ratio $(v)=0.3$.

- Density of support plastic material $\left(\rho_{\mathrm{s}}\right)=980 \mathrm{~kg} / \mathrm{m}^{3}$.

\section{Earthquake Data}

The spherical tank was analyzed under the impact of the earthquake that Iraq was exposed to in 2017 with a magnitude of 7.2 on the Richter scale, which is the most severe earthquake Iraq has been subjected to in recent decades. Acceleration values which were adopted in this study were taken from the earthquake stations records of the Seismic Iraqi Meteorological Organization and Seismology/ Ministry of Transportation, Baghdad, Iraq (unpublished data, 2018),. The records were transformed as time versus acceleration history. The most influential part with higher values of acceleration with time duration of 1.62 seconds was adopted in the present work, as shown in Figure 2.

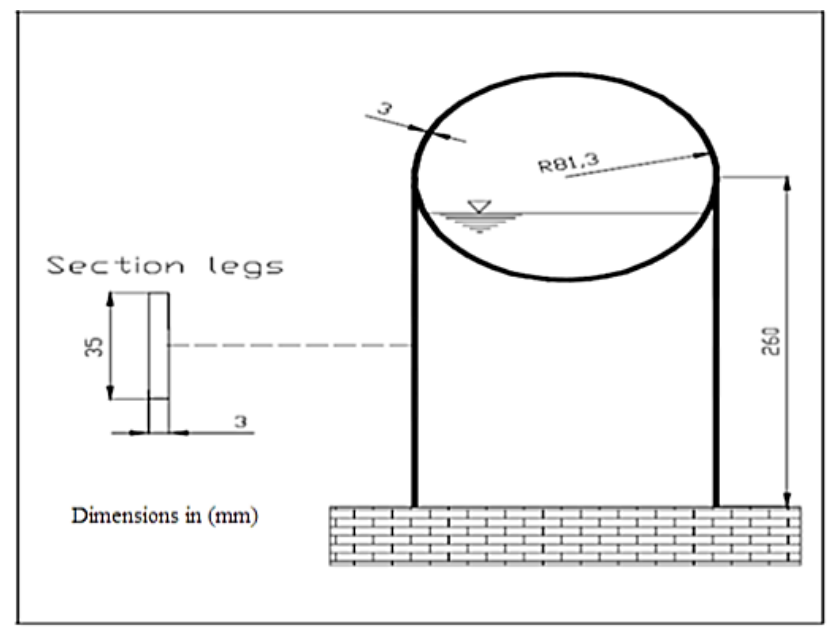

Figure 1: Details of spherical elevated tank [12] 


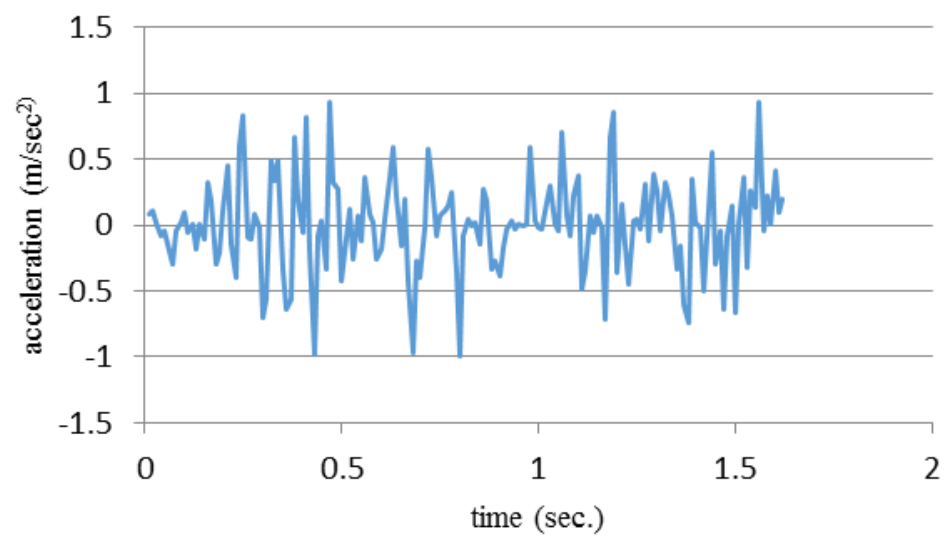

Figure 2: Earthquake time versus acceleration history

\section{Simulation Software}

There are a lot of analysis programs dealing with seismic analysis of the structures. In this study, the ANSYS software has been selected. ANSYS Mechanical is a workbench application capable of performing a variety of engineering simulations, including stress, thermal, vibration, thermo-electric, and static simulations.

\section{Modeling}

\section{A. Finite Element Formulation}

The finite element method is usually used to find approximate solutions for structures having complicated shapes and loading arrangement. In this research, FEM is used to model the elevated tank system as a general method of stress and deformation analysis. Container walls are modeled with quadrilateral shell181 element (with four nodes and six degrees of freedom per node; three translations and three rotations). Figure 3-a shows the shell181 element geometry [10].

The support system is modeled as beam 188 elements. Beam188 is suitable for analyzing slender to moderately beam structures [10]. The element is based on a Timoshenko beam theory which includes shear-deformation effects. The element provides options for unrestrained warping and restrained warping of cross-sections. Beam 188 element is a linear, quadratic, or cubic two-node beam element in 3-D. This element has six or seven degrees of freedom at each node. These include translations in the $\mathrm{x}, \mathrm{y}$, and $\mathrm{z}$ directions and rotations about the $\mathrm{x}, \mathrm{y}$, and $\mathrm{z}$ directions. A seventh degree of freedom (warping magnitude) is optional. This element is well-suited for linear, large rotation, and/or large strain nonlinear applications. Figure 3-b shows beam 188 element geometry [10].

\section{B. Acoustic Fluid Analysis}

In acoustical fluid-structure interaction problems, the structural dynamic equation needs to be considered along with the Navier-Stokes equations of fluid momentum and the flow continuity equation. The dynamic equilibrium equation of finite element systems can generally be expressed as [10]:

$\mathrm{M}_{\mathrm{c}} \ddot{\mathrm{u}}_{\mathrm{c}}+\mathrm{C}_{\mathrm{c}} \dot{\mathrm{u}}_{\mathrm{c}}+\mathrm{K}_{\mathrm{c}} \mathrm{u}_{\mathrm{c}}=\mathrm{F}(\mathrm{t})$

Where $M_{c}, C_{c}, K_{c}$, and $F(t)$ is the; structuralmass, damping, stiffnessmatrices, and dynamicloadvector respectively.

The acoustic wave equation given below is based on the following:

- The fluid incompressible (density change due to pressure variations)

- The fluid is inviscid (No viscous dissipation).

- There is no mean flow of fluid.

- The mean density and pressure are uniform throughout the fluid. 


$$
\frac{1}{C^{2}} \frac{\partial^{2} P}{\partial t^{2}}-\nabla^{2} P=0
$$

Where $C$ the speed of pressure is wave; $P$ is the acoustic hydrodynamic pressure; $t$ is time and $\nabla^{2}$ is Laplace operator.

An acoustic analysis calculates either the propagation properties of pure acoustic waves in the given environment or the coupled acoustic fluid structural interaction (FSI).In this research, Fluid30 element was used to model the fluid medium and the interface in fluid-structure interaction problems. The governing equation for acoustics, namely the $3-\mathrm{D}$ wave equation has been discretized taking into account the coupling of acoustic pressure and structural motion at the interface. The element node has four degrees of freedom period: translations in the nodal (x, y and $\mathrm{z}$ ) directions, and pressure. The translations are applicable only at nodes on the interface. Acceleration effects like those in sloshing problems can be included. Figure 3-c show fluid 30 element geometry [10].

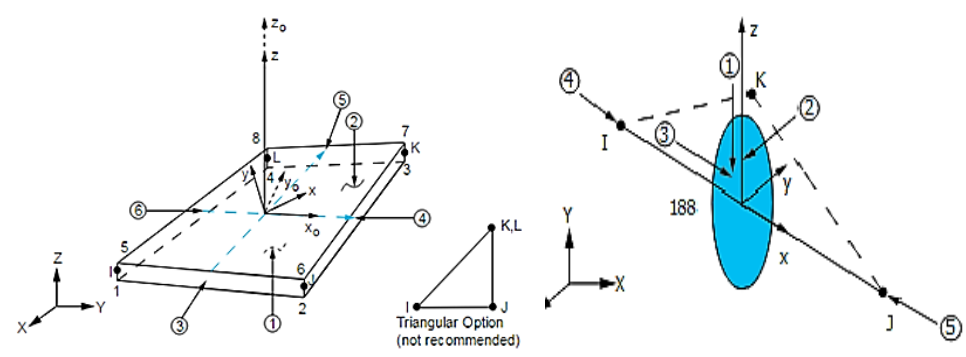

(a)

(b)

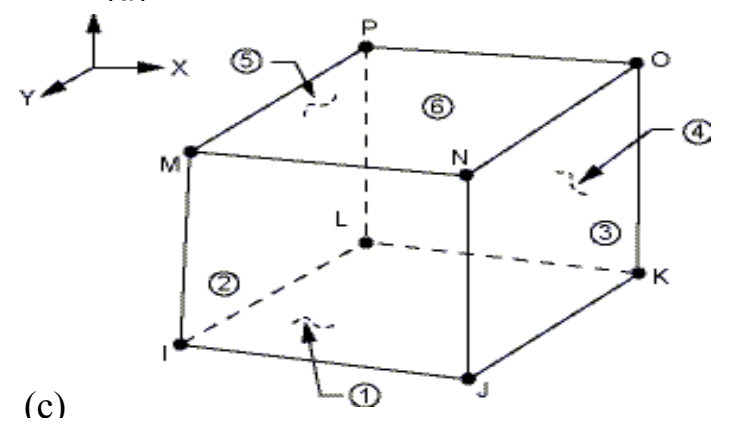

Figure 3: Elements geometry; (a) Shell 181 element, (b) Beam 188 element, (c) Fluid 30 element[10].

\section{Model Verification and Seismic Analysis}

The natural frequency of the tank was computed for the three fullness ratio proposed in the spherical tank $(0.00 \%, 53.30 \%$ and $71.11 \%)$ and the results were compared with the experimental results of O.Curadelli et al. (2008)[12]. The discrepancy index and root mean square error (RMSE) were adopted for comparison purposes.

For the same water levels, stability of the tank was determined by computing the displacement at nine points by trying to cover all parts of the tank. Three points were taken on the body of the tank itself ; the first point is located at the top of the tank (p1), the second in the middle of the tank (p2) and the third was located at the bottom of the tank (p3). The same is true for the supports where three points were taken first in the top of the support, the second one is located in the middle and the last was taken at the bottom for both left and right supports, which marked as (pr) for right and (pl) for the left. Subsequently, the displacement was computed for all points proposed in three directions (X, $\mathrm{Y}$ and Z). Figure 4 shows the Finite Element Mesh and distribution of the selected points for the displacement analysis. However, the overall time period of the earthquake was taken to be $1.62 \mathrm{sec}$. Within this period, the displacement and deflected shape of the tank were displayed in four different time intervals $(0.2,0.6,1$ and $1.62 \mathrm{sec})$.

Furthermore, the stresses were observed for seven points on structure, as shown in Figure 5, the same three points of the tank body, which were already marked, and two points for each support 
named as prs 1 and prs2 for the top quarter and bottom quarter of the right support, respectively, with pls1 and pls2 for the top quarter and bottom quarter of the left support, respectively.

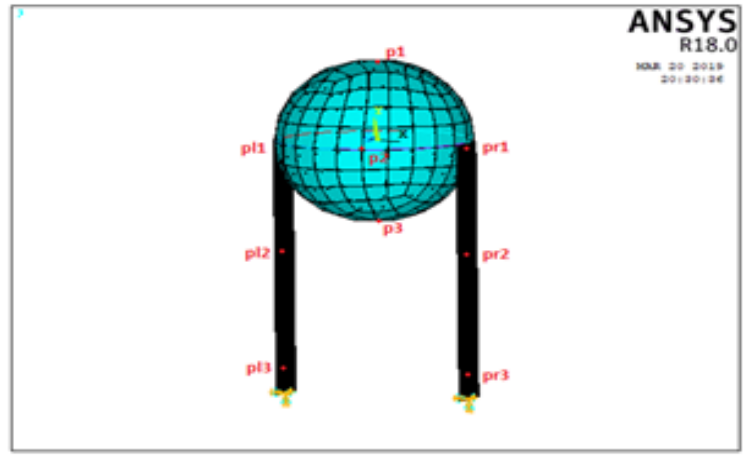

Figure 4: ANSYS Finite Element Mesh of the spherical tank

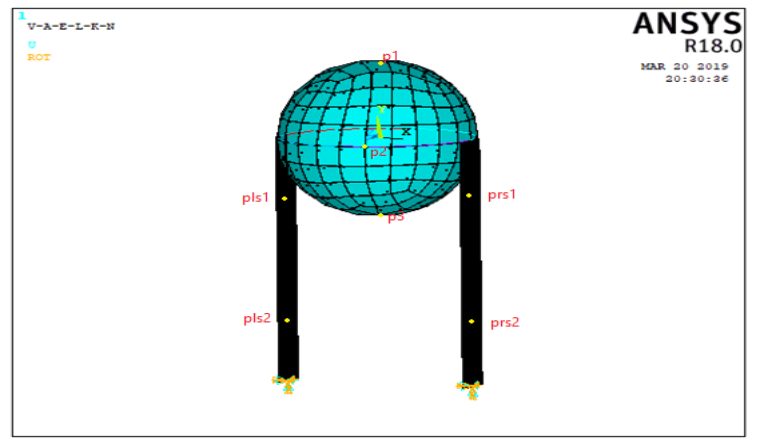

Figure 5: The distribution of stress analysis points

\section{RESULTS AND DISCUSSION}

\section{Verification of Dynamic Behavior}

According to the methodology of verification, three fullness ratios were taken to verify the used elements and test the dynamic behavior of the spherical tank by using the ANSYS software. The natural frequency of each fullness ratio was computed. These frequencies were compared to that of O.Curadelli et al. (2008) [12] experimental result. The discrepancy and RMSE were computed and used as performance indicators, see Table I. The computed discrepancy and RMSE were not greater than $10 \%$ and $20 \%$, respectively. Consequently, these indicators illustrates good agreement between the computed (using FEM based model) and the measures (Experiment of [12]).

TABLE I: Analysis of natural frequency to verify the Model.

\begin{tabular}{|c|c|c|c|c|c|}
\hline \multirow{2}{*}{ Mode No. } & \multirow{2}{*}{$\begin{array}{c}\text { Fullness } \\
\text { ratio (\%) }\end{array}$} & \multicolumn{2}{|c|}{ Natural frequency $(\mathrm{Hz})$} & \multirow{2}{*}{$\begin{array}{c}\text { Discrepanc } \\
\text { y }(\%)\end{array}$} & \multirow{2}{*}{$\begin{array}{c}\text { RMS } \\
\text { E }\end{array}$} \\
\hline & & Experimental [12]. & Model, Present Study & & \\
\hline 1 & 0.00 & 4.9 & 4.8 & 2 & 0.05 \\
\hline 2 & 53.30 & 4.3 & 4.6 & 6.9 & 0.15 \\
\hline 3 & 71.11 & 4.2 & 4.6 & 9.5 & 0.2 \\
\hline
\end{tabular}

\section{Analysis of Earthquake Effect}

The good agreement obtained from the FEM analysis using ANSYS software for the analyzed spherical tank with comparison to O.Curadelli work encouraged the use of the numerical analysis to study behaviors more than what were performed in this work. A numerical parametric study was carried out to show earthquake analysis results for the stress and displacement and deformed shapes at different time intervals for the adopted spherical tank. 


\section{A. Structural Deformation}

Results of earthquake analysis were obtained for the three fullness ratios proposed in this study. The deformation was verified for the earthquake time for all fullness ratios in different oscillations times. As a selected case for display, Figure 6 explain the deformed (blue) and unreformed (black) shape in the time $1.62 \mathrm{sec}$ from the oscillations during the selected period of the tank in the empty $(0.00 \%$ fullness ratio) case as explained previously.

\section{B. Sloshing Effect}

In order to investigate the movement of water inside the tank and the impact of sloshing, Figure 7 shows the distribution of the displacement on the volume of the water in the case of $53.3 \%$ fullness ratio. A point ( $\mathrm{p}$ ) has been taken on a fluid surface as shown in Figure 7 to compute the displacement (D) variation with time, see Figure 8. The sloshing of fluid was also observed as illustrative in Figure 9.

It can be indicated from Figure 8 that the maximum recorded value of the displacement $(1.2 \mathrm{e}-2$ $\mathrm{m})$ at time $1.4 \mathrm{sec}$ was about eight times more than the minimum recorded displacement $(-0.15 \mathrm{e}-2$

$\mathrm{m})$ at time $0.2 \mathrm{sec}$ which represents the least displacement.

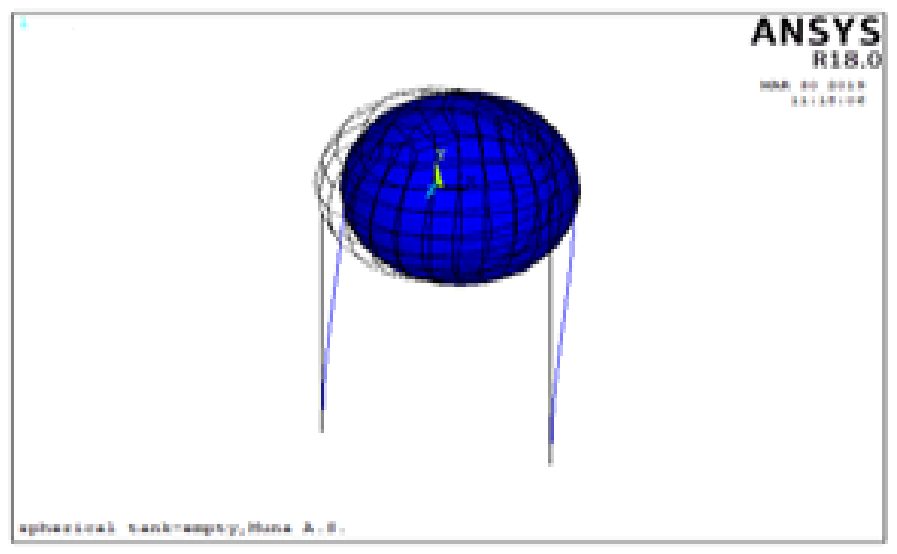

Figure 6: Structural deformation

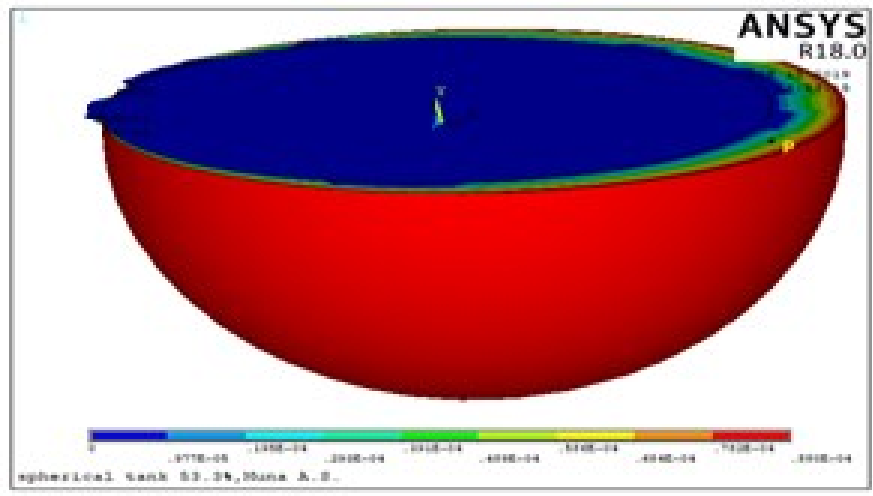

Figure 7: Displacement distribution of water 


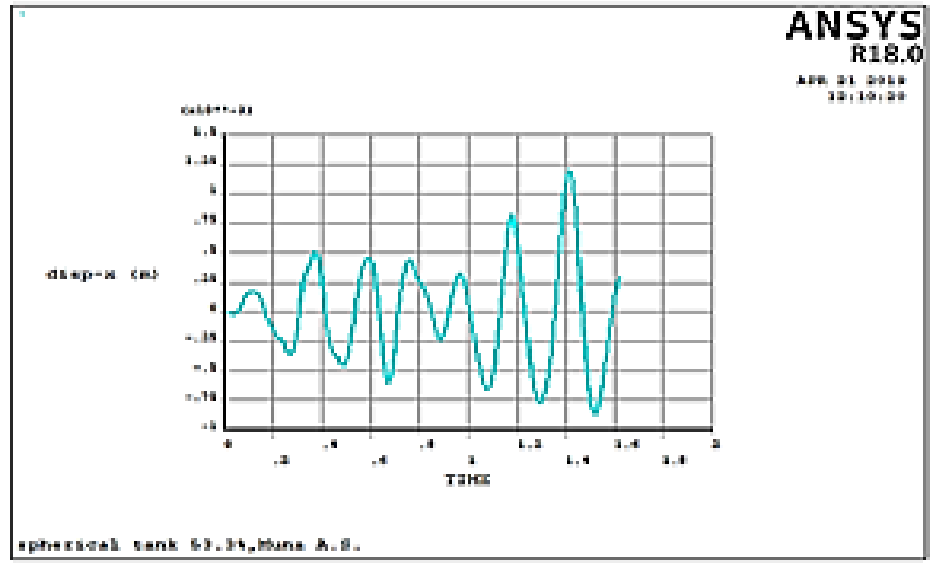

Figure 8: Displacement of point (p) on the water surface

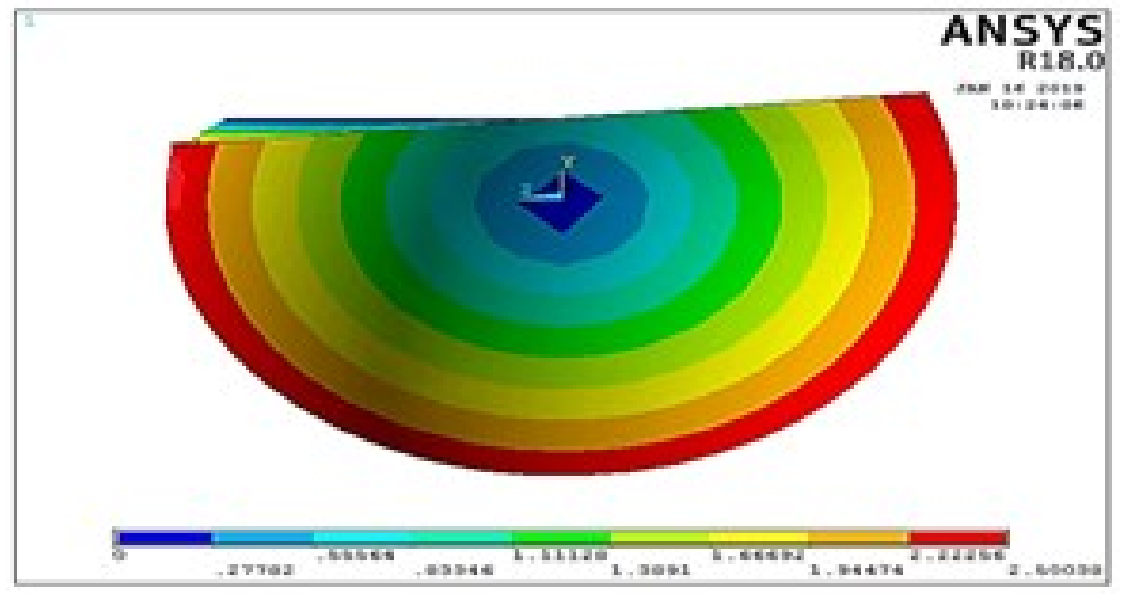

Figure 9: Sloshing effect

\section{Structural Displacement}

The displacement, for each fullness ratio, was computed in three directions for the tank body itself (three points), for the right support (three points) and finally for the left support (three points) as already mentioned in the seismic analysis methodology. The computed structural displacement via forms for each fullness ratio is illustrated in Figures 10 to12.

For the displacement in $\mathrm{x}$-direction for the points on the tank body (p1, p2,and $\mathrm{p} 3$ ), it was found that very little difference in the two cases with a ratio of water (53.30 and 71.11\%) from the empty case. This is almost similar to the effect on both supports with a slight increase in the fullness ratio of $53.30 \%$ for the other two cases in the right support while a zero displacement was computed for the points pr 3 and $\mathrm{pl} 3$ in the bottom of the supports. The highest displacement in y-direction was in the middle of the tank body at point $\mathrm{p} 2$ in both cases of 53.30 and $71.11 \%$ fullness ratios. Whereas, almost no displacement $(\mathrm{D} \approx 0)$ in the case of $0.00 \%$ fullness ratio. However, the case of $53.30 \%$ fullness ratio has the highest displacements even in the top point (p1). While, the bottom of the tank point $\mathrm{p} 3$ has a very simple displacement with the presence of water and almost nothing in the empty state. For both supports, y-displacements have little variation in all cases with a slight increase in empty tank and virtually no displacement in $\mathrm{pr} 3$ and $\mathrm{pl} 3$ in the bottom of the supports. Zdisplacement at the top of the tank (p1) in $53.30 \%$ fullness ratio is higher than that of $71.11 \%$ fullness ratio and varies significantly from the empty where the displacement is very little. The same is almost true at the bottom of tank body (at point p3) while the opposite occurred at point p2 in the middle of tank body where a zero displacement in both cases of presence of water and insignificant in the empty case. In right support the maximum value of displacement was almost the same for the two fullness ratios; $53.30 \%$ and $71.11 \%$ with a variation in the trend of displacement for the rest of time, while the computed displacement in point pl1 for the left support in the $71.11 \%$ fullness ratio 
was half than that of the $53.30 \%$ fullness ratio. Generally, pr3 and $\mathrm{pl} 3$ at the bottom of the supports have zero z-displacements.

\section{Stresses Analysis}

On the other hand, stress distribution was observed in each fullness ratio of the tank. Figure 13 illustrates the results of stress analysis of the spherical tank body for the considered three points under the effect of an earthquake. It was observed that the stress in the tank body reaches the highest levels in the top of the tank in the case of the empty tank, unlike other cases with the presence of water the upper limits were in the middle of the body of the tank. As well, stresses with time for the supports were stated in Table II for the points marked before to both right and left support. The two indicated points for each support, stresses were roughly equal to both supports in each case of study, although the fullness ratio $53.3 \%$ has the highest stress in the right support while the right support at the empty case records the least stress.
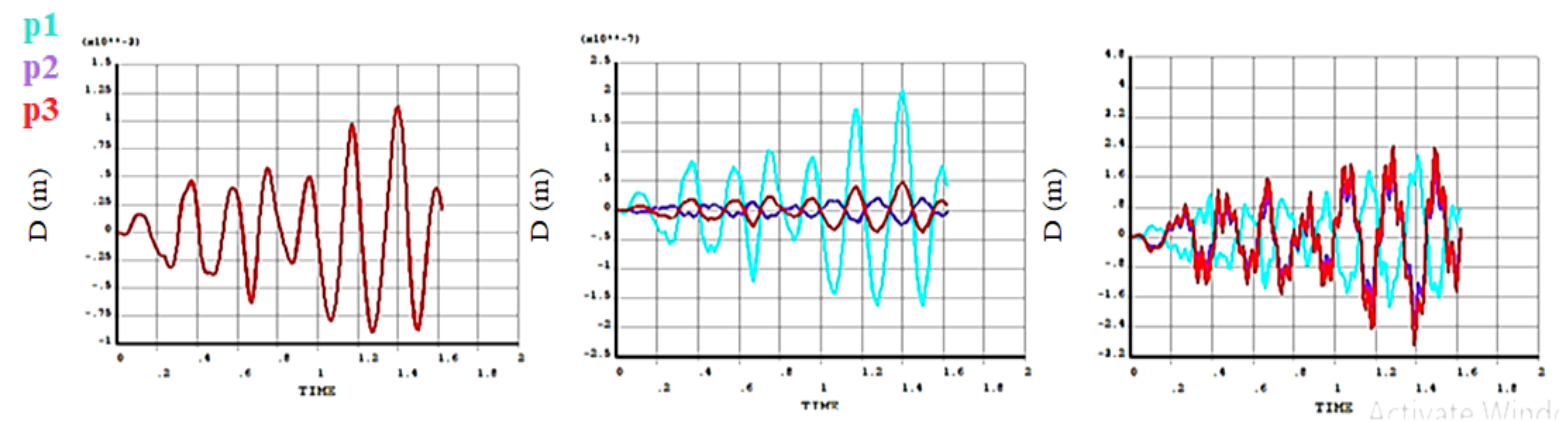

(a1) (a2) (a3)

a: (a1) in $x$-direction, (a2) in $y$-direction, (a3) in $z$-direction

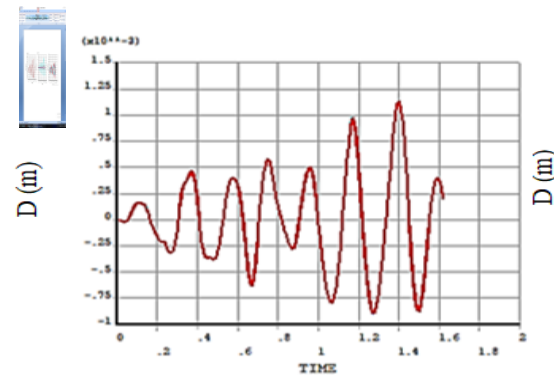

(b1)

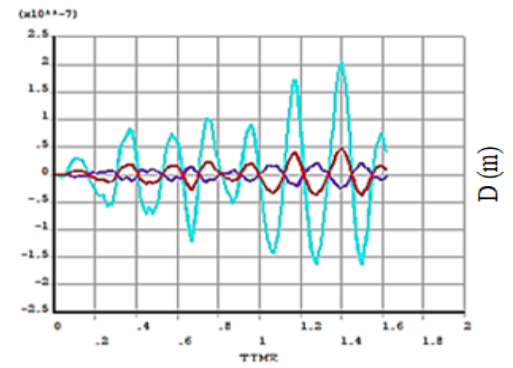

(b2)

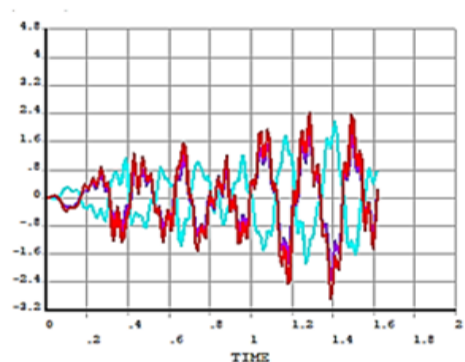

(b3)

b: (b1) in x-direction, (b2) in y-direction, (b3) in z-direction

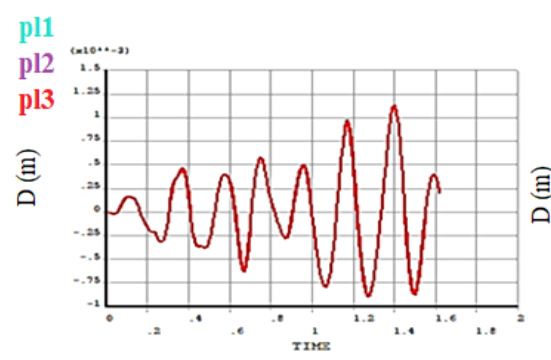

(c1)

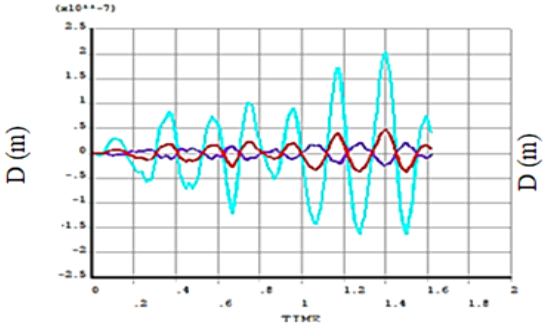

(c2)

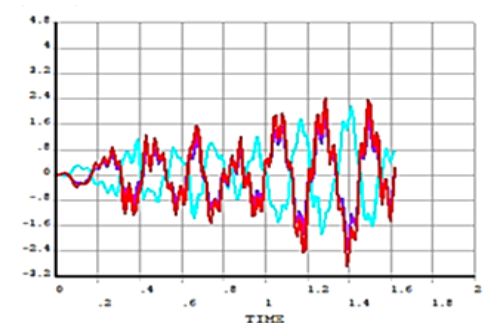

(c3)

c: (c1) in x-direction, (c2) in y-direction, (c3) in z-direction

Figure 10: Structural displacement under the effect of earthquake for $0.00 \%$ fullness ratio;a- Tank Body, b- Right support, c- Left support 


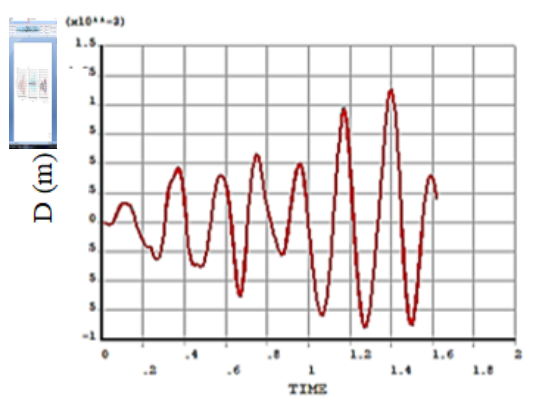

(a1)

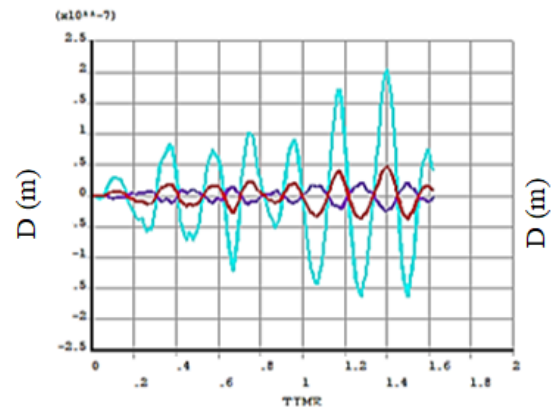

(a2)

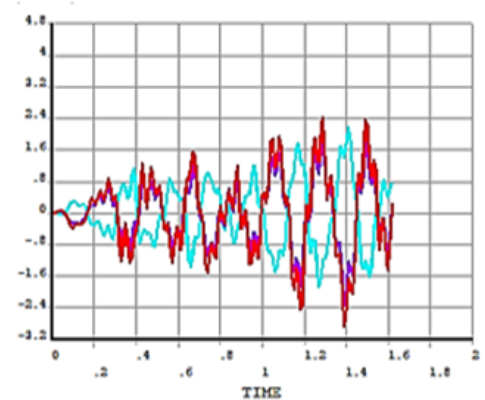

(a3)

a: (a1) in x-direction, (a2) in y-direction, (a3) in z-direction.

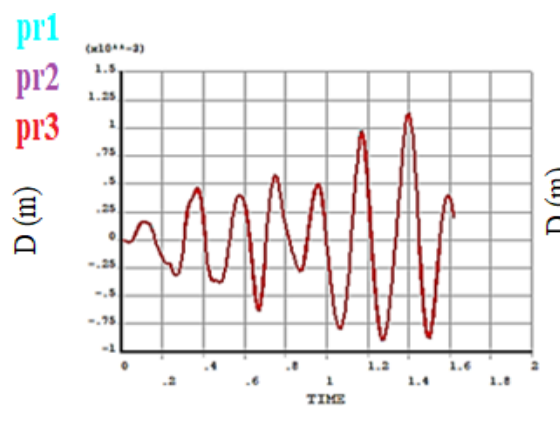

(b1)

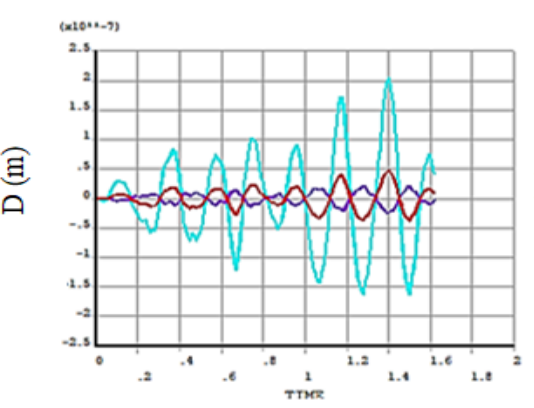

(b2)

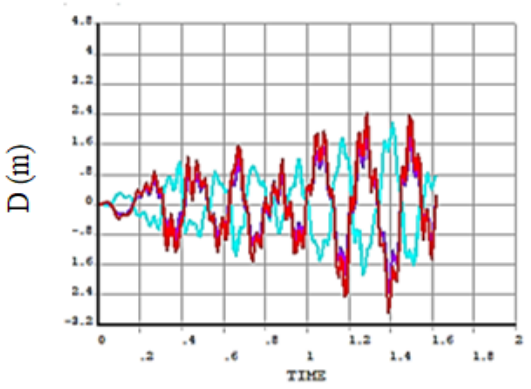

(b3)

b: (b1) in x-direction, (b2) in y-direction, (b3) in z-direction.

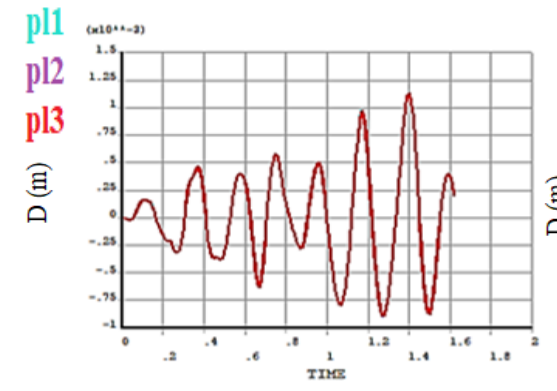

(c1)

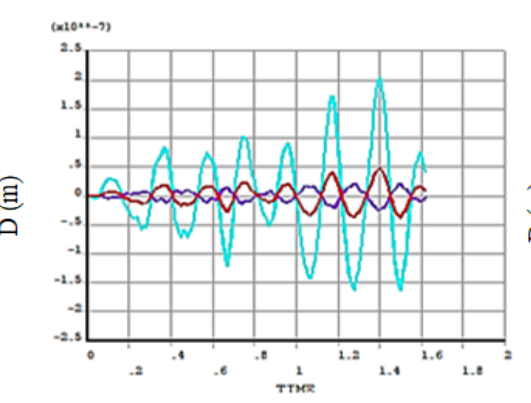

(c2)

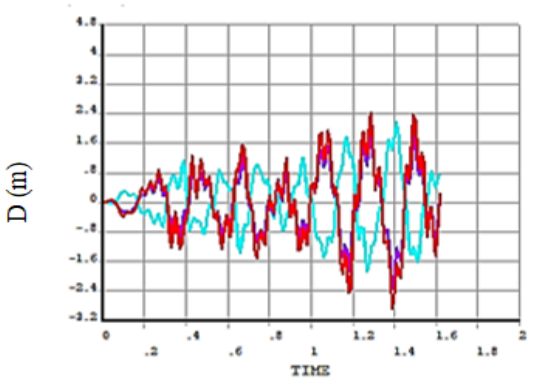

(c3)

c: (c1) in x-direction, (c2) in y-direction, (c3) in z-direction.

Figure 11: Structural displacement under the effect of earthquake for $53.30 \%$ fullness ratio;a- Tank Body, b- Right support, c- Left support 


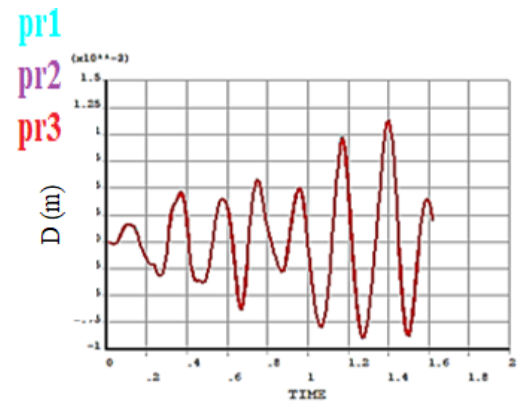

(a1)

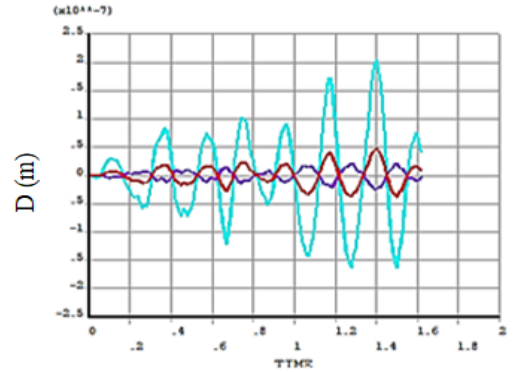

(a2)

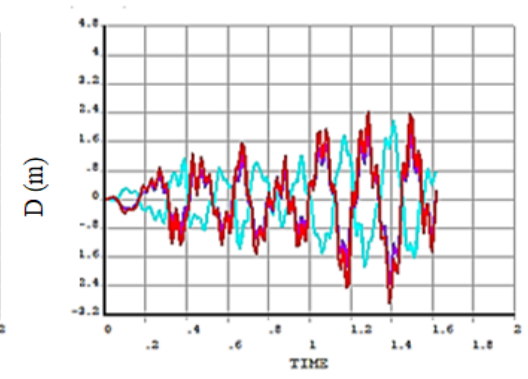

(a3)

a: (a1) in $x$-direction, (a2) in y-direction, (a3) in z-direction.

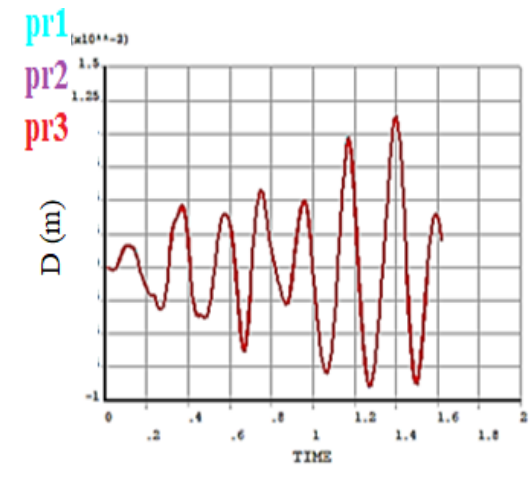

(b1)

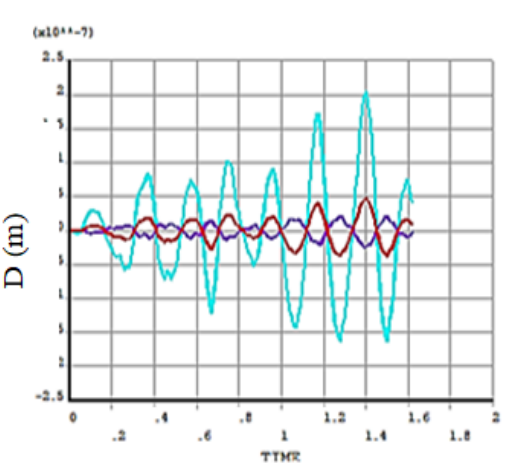

(b2)

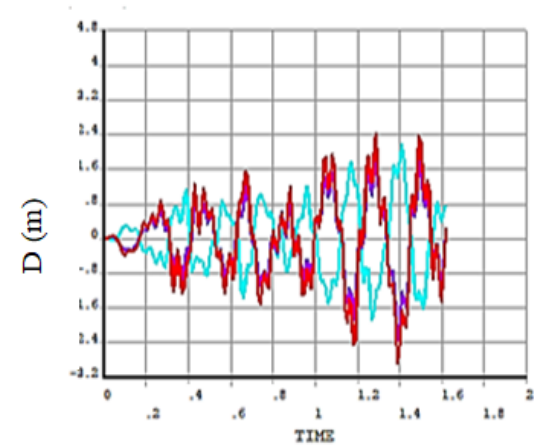

(b3)

b: (b1) in x-direction, (b2) in y-direction, (b3) in z-direction.

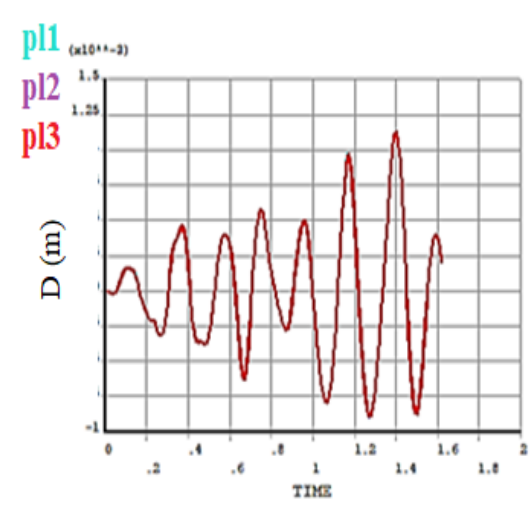

(c1)

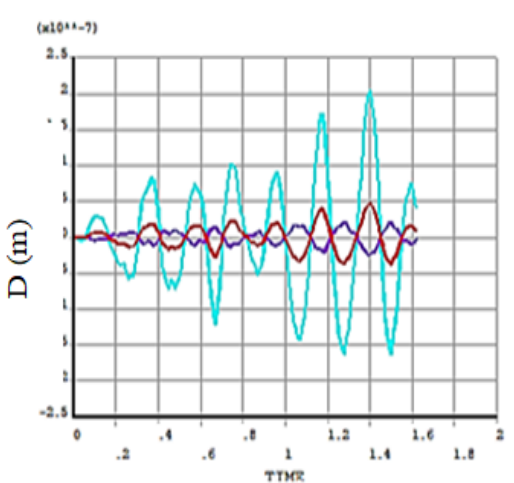

(c2)

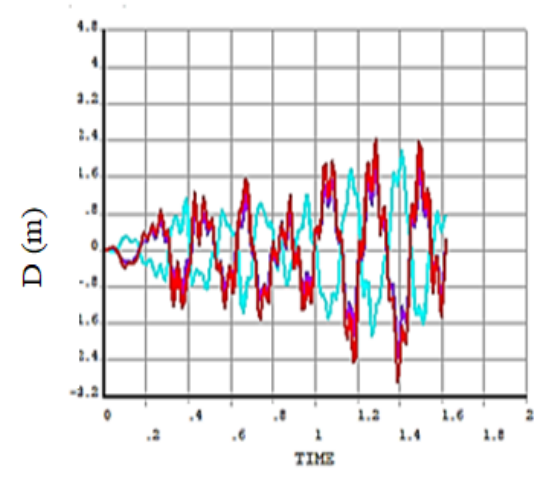

(c3)

c: (c1) in x-direction, (c2) in y-direction, (c3) in z-direction.

Figure 12: Structural displacement under the effect of earthquake for $\mathbf{7 1 . 1 1 \%}$ fullness ratio;a- Tank Body, b- Right support, c- Left support 


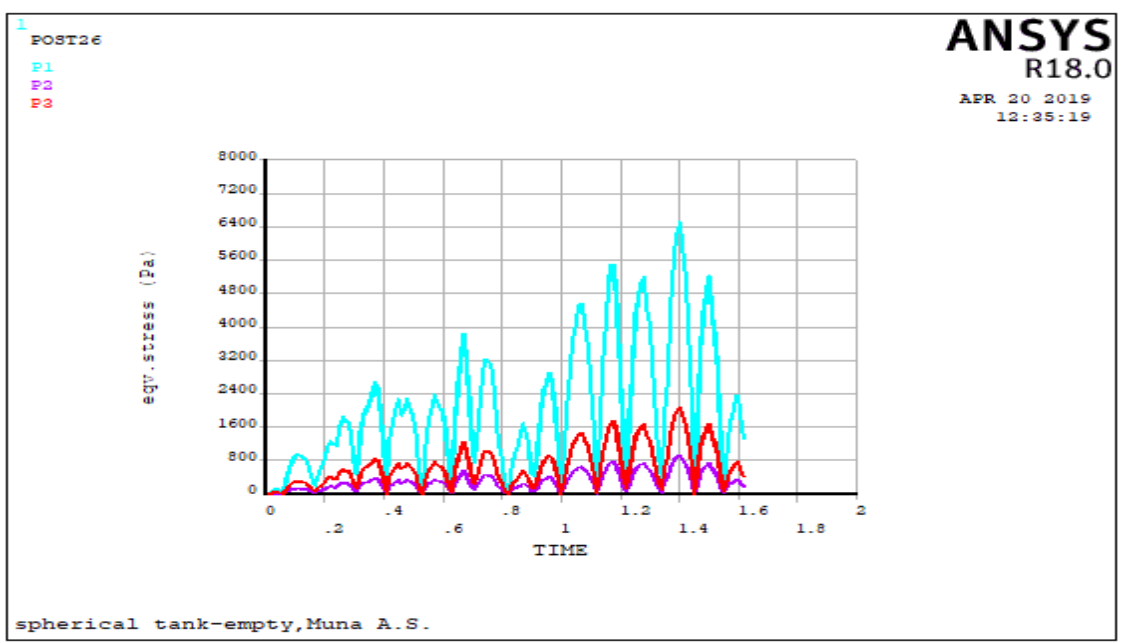

(a)

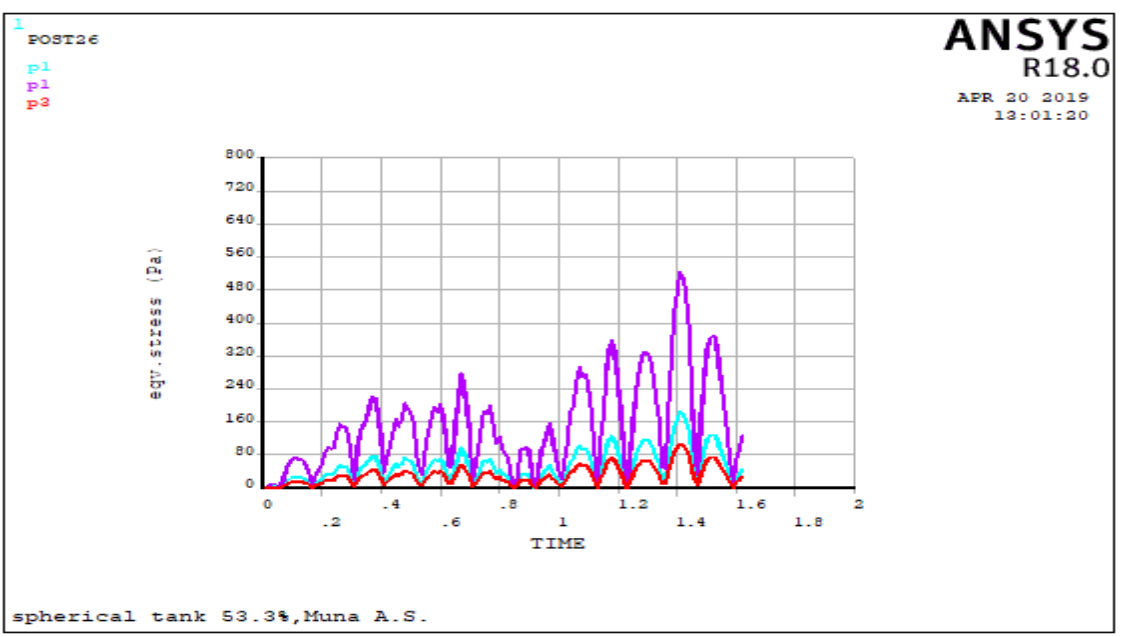

(b)

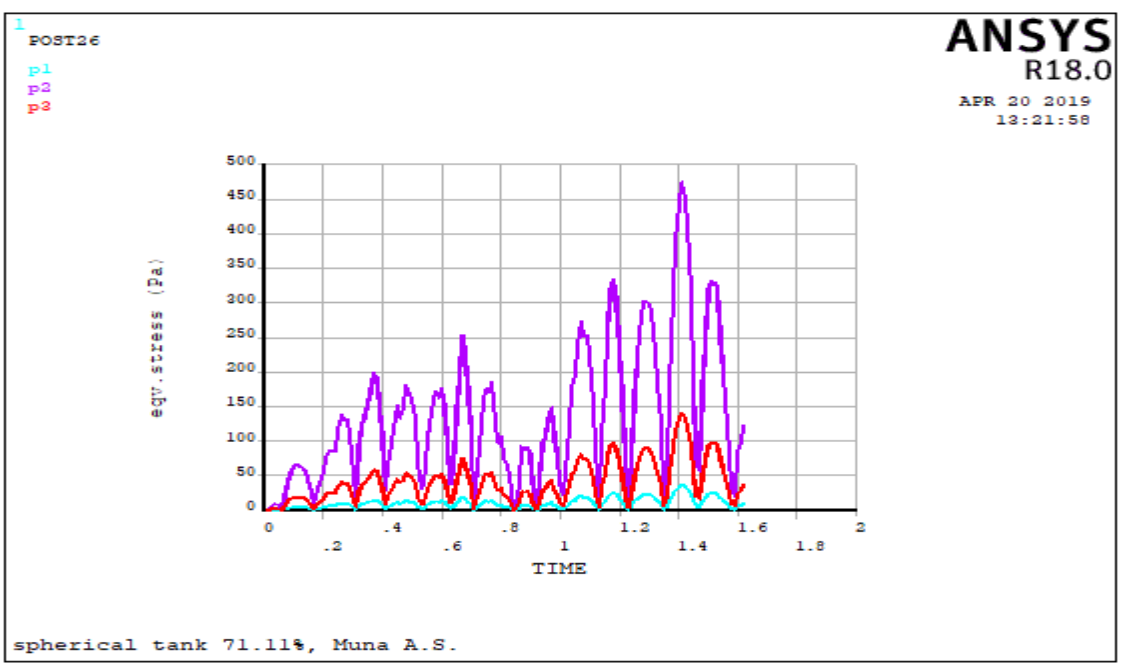

(c)

Figure 13: Stress distribution in the spherical tank body under the effect of the earthquake; a $0.00 \%$ fullness ratio, $b-53.30 \%$ fullness ratio, $c-71.11 \%$ fullness ratio 
TABLE II: Stress distribution in a spherical tank supports under the effect of an earthquake.

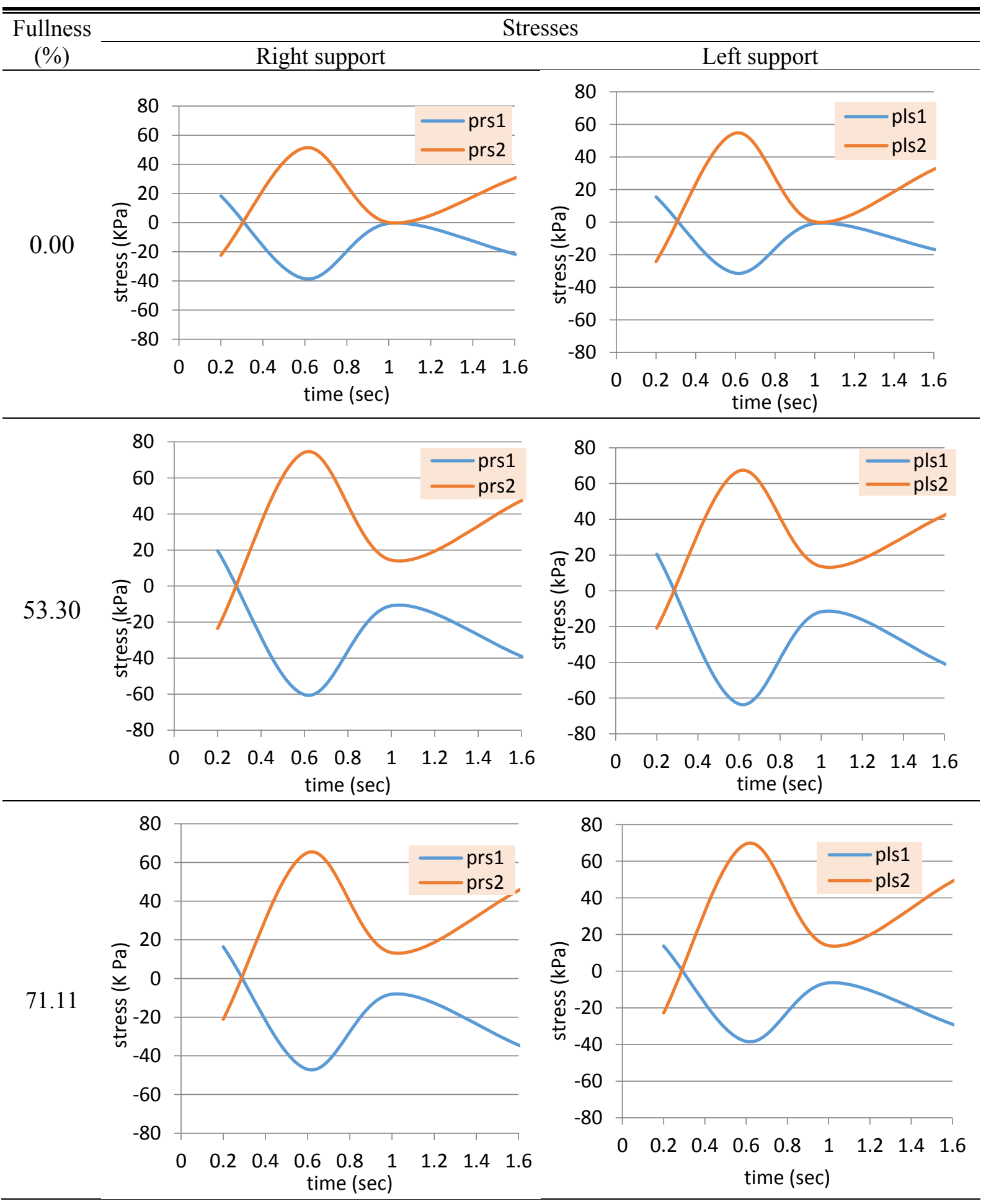

\section{Conclusion}

In this study, the dynamic responses of a spherical elevated storage tank subjected to earthquake are studied and through the results the following points were concluded:

1) High agreement achieved from the ANSYS results with comparison to the experimental work of the verified research for all the chosen cases of fullness ratios, even if it can be noted that the results of the present work of the empty tank are very close to that of the previous experimental work, still the other cases had good results. This means that the selected element type and the 
method of analysis are applicable and it is possible to implement the elements used by other researchers.

2) The displacements, as noticed, in seismic analysis are so large that the elevated tank can lose stability even though the internal forces are small.

3) It is clear that the water has a very high influence on the tank stability under the effect of the earthquake conditions.

4) It was obvious that the influence of earthquake is more effective in the direction of the earthquake and deduces that in the case of $53.3 \%$ fullness ratio is relatively more dangerous from the case of $71.11 \%$ and this is due to the impact of water movement, which is more severe in the first case.

5) Natural frequency is decreased when filling ratio is increased giving the higher ratio at the empty tank case.

6) The distribution of stresses in the supports recorded its highest score in the case of 53.3\% specifically right support while the highest levels in the top of the tank body were observed in the case of the empty tank.

\section{Acknowledgment}

We would like to particularly thank the University of Technology-Iraq, for their valuable scientific assistance and support. Many institutions contributed to this research in various ways. We would like to thank the Baghdad Governorate for providing the required data and technical assistance.

\section{References}

[1] M. S. Mhetreand G. R. Patil, "Analysis of Elevated Water Storage Structure Using Different Staging System", IOSR Journal of Mechanical and Civil Engineering (IOSR-JMCE) e-ISSN: 2278-1684, p-ISSN: 2320-334X PP 21-32, 2015.

[2] H. H. Karim, Z. W.Samueel, and D. A.Abdul Hussein, "Correlation of Soil Liquefaction Potential Index and Geotechnical Properties for Baghdad City, Iraq”. Engineering and Technology Journal, 38(6A), 813-824. https://doi.org/10.30684/etj.v38i6A.189, 2020.

[3] Q. A.Hasan, S. F.Al-Wakel, and Z. R.Zaidan,"Numerical Investigations on Seismic Response of Structures under the Effect of Infinite Boundary of Soil-Structure Interaction". Engineering and Technology Journal, 37(12A), 516-521. Retrieved from http://engtechjournal.org/index.php/et/article/view/187, 2019.

[4] A. A.Hussein, M. A. Al-Neami, and F. H. Rahil,"Evaluation of the Hydrodynamic Pressure Effect of Cylindrical Liquid Storage Tank on The Granular Soil Behavior Under Seismic Excitation". Engineering and Technology Journal, 39(1A), 64-78. https://doi.org/10.30684/etj.v39i1A.1697, 2021.

[5] G. W. Housner, "The Dynamic Behavior of Water Tanks",Bulletin of the Seismological Society of America. Vol. 53, No. 2, pp. 381-387, 1963.

[6] M.A.Haroun, and M.K.Termaz, "Effects of soil-structure interaction effects on seismic response of elevated tanks". Soil Dynamics Earthquake Engineering, Vol. 11, No. 2, PP. 37-86, 1992.

[7] S.Seyoum, "Dynamic analysis of liquid containing cylindrical tanks",Msc thesis, university of Addis Ababa, October, 2005.

[8] S.Dutta, A.Mandal, and S.C.Dutta, "Soil-structure interaction in dynamic behavior of elevated tanks with alternate frame staging configurations". Journal of Sound and Vibration, Vol. 227, Issues 4-5, pp. 825-853, 2004.

[9] M. V.Gaikwad, and M.N.Mangulkar, "Comparison between Static and Dynamic Analysis of Elevated Water Tank", International Journal of Scientific \& Engineering Research, Volume 4, Issue 6, ISSN 2229-5518, 2013.

[10] ANSYS Manual, Version18. (2018).

[11] H. Suchita, and H.Manoj, "Seismic performance of Elevated Water Tank", International Journal of Advanced Engineering ResearchandStudies,Vol. I, 2011.

[12] O. Curadelli, D.Ambrosini, A. Mirassoand M. Amani, MecánicaComputacional Vol XXVII, págs. 19071920 (artículocompleto) Alberto Cardona, Mario Storti, Carlos Zuppa, 2008. 